\title{
Perakendecilikte drone ile ürün teslimatının tüketicilerin davranışsal niyetlerine etkisi
}

\section{The effect of product delivery with drones on consumers' behavioural intentions in retailing}

${ }^{1}$ Arş. Gör. Dr., Van Yüzüncü Yıl Üniversitesi, Ercis İșletme Fakültesi, İşletme Bölümü, Van, Türkiye zubeyircelik@yyu.edu.tr

ORCID: 0000-0003-1692-9378

${ }^{2}$ Dr. Öğr. Üyesi, Van Yüzüncü Y1l Üniversitesi, Ercis İşletme Fakültesi, İşletme Bölümü, Van, Türkiye ibrahimaydin@yyu.edu.tr

ORCID: 0000-0002-0720-364X

Sorumlu Yazar/Corresponding Author: Zübeyir Çelik,

Van Yüzüncü Yıl Üniversitesi, Erciş İşletme Fakültesi, İşletme Bölümü, Van, Türkiye zubeyircelik@yyu.edu.tr

Başvuru/Submitted: 23/08/2021

Revizyon/Revised: 1/10/2021

Kabul/Accepted: 10/10/2021

Yayın/Online Published: 25/12/2021

Atıf/Citation: Çelik, Z., \& Aydın, İ., Perakendecilikte drone ile ürün teslimatının tüketicilerin davranışsal niyetlerine etkisi, bmij (2021) 9 (4): 14221436, doi: https://doi.org/10.15295/bmij.v9i4.1919

\author{
Zübeyir Çelik ${ }^{1}$ \\ İbrahim Aydın²
}

Öz

Bu çalışmanın amacı, perakendecilikte drone ile ürün teslimatının tüketicilerin davranışsal niyetleri üzerindeki etkisini incelemektir. Online anket ve deney yöntemi kullanılarak katılımcılardan toplanan 404 veri için istatistiksel analizler yapılmıştır. Tek örneklem t-testi sonuçlarına göre; drone ile ürün teslimatı, tüketicilerin drone'ları alışveriş için kullanma davranışsal niyetleri üzerinde olumlu ve anlamlı bir etkiye sahiptir. Bağımsız örneklemler t-testi sonuçlarına göre; erkek ve kadınlar arasında ve tek yönlü varyans analizi sonuçlarına göre; $X, Y$ ve Z jenerasyonları arasında tüketicilerin drone'ları alışveriş için kullanma davranışsal niyetlerinde anlamlı bir farklılık yoktur. Basit doğrusal regresyon analizi sonuçlarına göre; algılanan yenilikçilik, hızın göreceli avantajı, fonksiyonel motivasyon, hedonik motivasyon, algılanan güven ve problem farkındalığı drone kullanmaya yönelik tutum üzerinde olumlu ve anlamlı bir etkiye sahiptir. Ancak algılanan riskin drone kullanmaya yönelik tutum üzerindeki olumsuz etkisi anlamlı değildir. Öte yandan drone kullanmaya yönelik tutumun drone kullanma niyeti üzerinde olumlu ve anlamlı bir etkisi bulunmaktadır. Bu çalıșma, tüketicilerin perakendecilikte drone ile ürün teslimat hizmetlerini kullanma konusundaki davranışsal niyetlerini başarılı bir şekilde açıklamaktadır.

Anahtar Kelimeler: Drone, Ürün Teslimatı, Perakendecilik, Davranışsal Niyet

Jel Kodları: M31, L81, L86

\begin{abstract}
This study examines the effect of product delivery with drones on consumers' behavioural intentions in retailing. Statistical analyzes were made for 404 data collected from the participants using the online survey and experiment methods. According to the results of the one-sample t-test, product delivery with a drone has a positive and significant effect on consumers' behavioural intentions to use drones for shopping. According to the independent samples t-test, between males and females, and according to the one-way analysis of variance; among $\mathrm{X}, \mathrm{Y}$, and $\mathrm{Z}$ generations, there is no significant difference in consumers' behavioural intentions to use drones for shopping. According to the simple linear regression analysis, perceived innovativeness, the relative advantage of speed, functionally motivation, hedonic motivation, perceived trust, and problem awareness have a positive and significant effect on the attitude towards drone use. However, the negative impact of perceived risk on drone use is not practical. On the other hand, attitude towards drone use has a positive and significant effect on the intention to use a drone. This study successfully explains consumers intentions to use product delivery services with a drone in retailing.
\end{abstract}

Keywords: Drone, Product Delivery, Retailing, Behavioural Intention

Jel Codes: M31, L81, L86 


\section{Extended Abstract}

\section{The effect of product delivery with drones on consumers' behavioural intentions in retailing}

\section{Literature}

\section{Research subject}

Drones are practical commercial applications of the future. Drone technology has many commercial applications. For example, transport is one of the leading commercial applications of drone technology. By using drone technology, it is possible to quickly deliver the order packages to the predetermined address of the customer without the need for much human intervention.

Drone models for commercial applications are actively promoted by leading retail company (brand) giants such as Amazon and Walmart for product delivery. Recently, the introduction of drone technology applications in the retail field has attracted the attention of researchers. As a result, there are recent applied studies on the use of drone technology for product delivery in the retail space in consumer research (Choe et al., 2021a, 2021b; Hwang \& Choe, 2019; Hwang \& Kim, 2019; Hwang et al., 2019a, 2019b; Hwang et al., 2020; Hwang et al., 2021; Khan et al., 2019; Kim \& Hwang, 2020; Kim et al., 2021; Mathew et al., 2021; Ramadan et al., 2017; Yoo et al., 2018).

\section{Research purpose and importance}

This study examines the effect of product delivery with drones on consumers' behavioural intentions in retailing. The difference of this study from the existing studies in the relevant literature is that it examines the effect of product delivery by drone on behavioural intentions in terms of perceived innovativeness, the relative advantage of speed, functional motivation, hedonic motivation, perceived trust, problem awareness, perceived risk, and attitude towards drone use. In addition, another difference of this study from existing studies is that it examines whether the behavioural intentions of consumers differ significantly in terms of gender and generations. Few studies investigate the effects of drone product delivery on consumers in retail. Considering that there are many studies, this study was carried out to contribute more to the relevant literature.

\section{Design and method}

The study is causal and was carried out with the quantitative research method. Experiment and online survey methods were used to collect data for this study. After watching video content about product delivery by drone, the participants answered the survey questions directed to them. The video content is intended for the customer to order the product in the e-retailer using the mobile application, the preparation and packaging of the product order, and the delivery of the product package to the customer's predetermined address by drone within a short period of thirty minutes. The name of the drone brand, the brand name of the mobile application, the product brand names and the brand name of the e-retail is not shown in the video content. So the research topic of this study is not for a specific brand or brand.

The scales used in the study were created by making studies suitable for the study.

The population of the study consists of 83 million 614 thousand 362 people (Turkey population), according to the Turkish Statistical Institute's 2021 data. The link of the online survey form was shared with social media applications, and the people who shared it were asked to share this link with their acquaintances. As a result, 409 questionnaire forms were obtained. By removing five incorrect questionnaires, data entry of 404 questionnaires into the SPSS 25 package program was made. According to the formula used and the Turkish population of 83 million 614 thousand 362 people, the sample of 404 people $(404>384)$ has a confidence level of over $95 \%$ (Krejcie and Morgan, 1970). As a result, 404 people reached by snowball sampling method constitute the study sample.

Single sample t-test, simple linear regression, independent sample t-test, and one-way analysis of variance were used in the study.

\section{Hypotheses}

Consumers have behavioural intentions to use a particular system (Davis et al., 1989). It is seen that there is no significant difference between genders and generations in terms of consumers' behavioural intentions regarding the use of target systems (Köse \& Yengin, 2018). Perceived innovativeness of drone product delivery significantly impacts drone use (Hwang et al., 2019b; Kim et al., 2021). The relative advantage of product delivery speed with drones significantly affects drone use (Yoo et al., 2018). The functional motivation of product delivery by drone has a significant impact on drone use (Hwang et al., 2019a; Mathew et al., 2021; Ramadan et al., 2017). The hedonic motivation of drone product delivery significantly impacts the attitude towards drone use (Hwang et al., 2019a; Hwang et al., 2021). The perceived trust of the target information system has a significant relationship with the attitude towards using the target information system $(\mathrm{Wu} \& \mathrm{Ke}, 2015)$. Product delivery by drone has a substantial impact on attitude towards using drones due to problems such as the environmental damage of product delivery with existing delivery methods such as motorcycles or cars (Hwang \& Kim, 2019; Kim \& Hwang, 2020). The perceived risk of product delivery by drone has a significant impact on drone use (Ramadan et al., 2017; Yoo et al., 2018). Attitudes towards drone use significantly impact behavioural intentions to use drones (Hwang \& Kim, 2019; Hwang et al., 2019a, 2019b; Hwang et al., 2021; Kim et al., 2021; Mathew et al., 2021; Ramadan et al., 2017).

In the light of the above information, the following hypotheses have been developed.

$\mathrm{H}_{1 a}$ : Product delivery by drone has a positive and significant effect on drone use intention.

$\mathrm{H}_{1 b}$ : There is no significant difference between genders regarding drone use intention.

$\mathrm{H}_{1 \mathrm{c}}$ : There is no significant difference between generations regarding drone use intention.

$\mathrm{H}_{2}$ : Perceived innovativeness has a positive and significant effect on the attitude towards drone use.

$\mathrm{H}_{3}$ : The relative advantage of speed has a positive and significant effect on the attitude towards drone use.

$\mathrm{H}_{4}$ : Functional motivation has a positive and significant effect on the attitude towards drone use.

$\mathrm{H}_{5}$ : Hedonic motivation has a positive and significant effect on the attitude towards drone use.

$\mathrm{H}_{6}$ : Perceived trust positively and significantly affects the attitude towards drone use. 
$\mathrm{H}_{7}$ : Problem awareness has a positive and significant effect on the attitude towards drone use.

$\mathrm{H}_{8}$ : Perceived risk has a negative and significant effect on the attitude towards drone use.

$\mathrm{H}_{9}$ : Attitude towards using a drone has a positive and significant effect on using a drone.

\section{Findings, discussion and results}

It was concluded that there is a positive and significant differentiation in the effect of drone delivery on consumers' behavioural intentions to use drone delivery for shopping. According to this result, in retail, drone delivery service is a promising technological new business model as it positively impacts consumers' behavioural intentions. Distribution costs are expected to decrease with the use of drones in retail. Electric drones will carry out distribution activities at a much more affordable price than the fuel costs of fossil fuel vehicles or the fees paid to cargo companies. In this case, businesses using drones will gain a cost advantage and competitive advantage against their competitors with high distribution costs. In addition, with the use of drones in short distances, fast delivery will be obtained compared to traffic density or long shipping processes. Again this will provide a competitive advantage against competitors who do not use drones and lead to customer loyalty with more customer preference. Another solid gain for using drones is that, unlike fossil fuels, it does not harm the environment. The use of electric drones for product delivery services, not vehicles running on fossil fuels that harm the environment, is an essential issue in the company's social responsibility. In addition, the fact that more people are aware of this issue with marketing communication activities will cause the business to gain more loyal customers. There is no significant difference between men and women in consumers' behavioural intentions to use drone delivery for shopping. There is no significant difference between the $\mathrm{X}, \mathrm{Y}$, and $\mathrm{Z}$ generations in consumers' behavioural intentions to use drone delivery for shopping. These results are similar to the study results in which the use of technology by consumers does not differ significantly in terms of gender (Kim \& Forsythe, 2008) and generations (Köse \& Yengin, 2018). Perceived innovativeness (Hwang et al., 2019b; Kim et al., 2021), the relative advantage of speed (Yoo et al., 2018), functional motivation (Hwang et al., 2019a; Mathew et al., 2021; Ramadan et al., 2017), hedonic motivation (Hwang et al., 2019a; Hwang et al., 2021), perceived trust (Wu \& Ke, 2015), and problem awareness (Hwang \& Kim, 2019; Kim \& Hwang, 2020) have a positive and significant effect on the attitude towards drone use, which is similar to the results of the studies in the relevant literature. It was seen that the negative impact of perceived risk on the attitude towards drone use was not significant. This result differs from some studies in the related literature (Ramadan et al., 2017; Yoo et al., 2018). On the other hand, it has been seen that the attitude towards drone use has a positive and significant effect on the intention to use the drone. This result is similar to many studies in the related literature (Hwang \& Kim, 2019; Hwang et al., 2019a, 2019b; Hwang et al., 2021; Kim et al., 2021; Mathew et al., 2021; Ramadan et al., 2017).

\section{Limitations and recommendations}

It should be noted that the research data are mainly collected from male, $\mathrm{Y}$ generation, university graduates, and participants whose monthly income varies between 5001-7500 TL. Therefore, the study results should be evaluated by considering the demographic characteristics of the participants. Furthermore, to generalize the results of this current study, it is thought that it will be helpful to conduct other studies in the future by collecting data from participants with different demographic characteristics.

In this study, the issue of product delivery with drones introduced in the retailing field is discussed to explain consumer behaviour. In addition, however, the effects of drone technology applications on consumers in areas such as shipping or the health sector can be examined.

It is estimated that people do not have sufficient mental ability to perceive the risks of this application because drone distribution has not yet found widespread application. However, with the general use of drones in the future, it is thought that people's risk perceptions towards this type of delivery may change, with the occurrence of incidents of falling on people due to technical malfunctions, causing damage to animals, cars and, goods, and these risks being the subject of news. Therefore, with the widespread use of drones in delivery, results that will be contrary to the results obtained in the study can be obtained. With similar studies in the future, it can be understood whether people's risk perception regarding drone delivery has changed.

Considering the advantages of drone distribution, which will be among the distribution applications of the future in the retail sector, it is recommended that companies adopt this practice early. 


\section{Giriş}

Drone teknolojisinin birçok ticari uygulaması bulunmakla birlikte, geleceğin de pratik ticari uygulamaları arasında yer almaktadır. Taşımacılık, drone'ların ana ticari uygulamalarından biridir. Drone'lar kullanılarak insan müdahalesine çok da gerek kalmadan sipariş paketlerinin hızlı bir şekilde müşterinin önceden belirlenen adresine ulaştırılması mümkündür.

Ticari uygulamalara yönelik drone modelleri, ürün teslimatı için Amazon ve Walmart gibi önde gelen perakende şirket (marka) devleri tarafından aktif olarak tanıtılmaktadır. Son zamanlarda drone teknolojisi uygulamalarının perakendecilikte tanıtılması araştırmacıların ilgisini çekmiş ve konu ile ilgili tüketici davranışlarının anlaşılmasına yönelik çoğu yakın zamanda yapılmış, uygulamalı çalışmalar bulunmaktadır (Choe, Kim ve Hwang, 2021a; Choe, Kim ve Hwang, 2021b; Hwang ve Choe, 2019; Hwang ve Kim, 2019; Hwang, Kim ve Kim, 2019a; Hwang, Lee ve Kim, 2019b; Hwang, Kim ve Kim, 2020; Hwang, Kim ve Lee, 2021; Khan, Tausif ve Javed Malik, 2019; Kim ve Hwang, 2020; Kim, Kim ve Hwang, 2021; Mathew, Jha, Lingappa ve Sinha, 2021; Ramadan, Farah ve Mrad, 2017; Yoo, Yu ve Jung, 2018). Yapılan çalışmaların sayıca az olduğu göz önüne alındığında özellikle ilgili literatüre daha fazla katkı sağlamak amacıyla bu çalışma gerçekleştirilmiştir. Bu çalışmanın sınırlılıkları göz önünde bulundurularak, çalışma sonunda araştırmacılara ve uygulayıcılara önerilerde bulunulmuştur.

$\mathrm{Bu}$ çalışmanın amacı, drone ile ürün teslimatının tüketicilerin drone kullanma niyetleri üzerindeki etkisini incelemektir. Çalışma, perakendecilikte drone ile ürün teslimatının tüketicilerin davranış niyetleri üzerindeki etkisini inceleyen az sayıdaki çalışmadan biridir. Çalışmanın ilgili literatürdeki mevcut çalışmalardan farkı, drone ile ürün teslimatının davranışsal niyetler üzerindeki etkisini, daha önce aynı çalışma konusu içinde değil, farklı çalışma konuları kapsamında değerlendirilen algılanan yenilikçilik, hızın göreceli avantajı, fonksiyonel motivasyon, hedonik motivasyon, algılanan güven, problem farkındalığı, algılanan risk ve drone kullanmaya yönelik tutum faktörleri açısından incelenmesidir. Ayrıca bu çalışmanın mevcut çalışmalardan bir diğer farkı, tüketicilerin davranışsal niyetlerinin drone ile ürün teslimatları, cinsiyet ve jenerasyonlar açısından anlamlı olarak farklılaşıp farklılaşmadığının incelenmesidir.

\section{Literatür incelemesi}

\section{Perakendede ürün teslimatı için drone kullanımı}

Drone'lar, müşterilere sipariş paketlerini belirli bir zaman aralığında doğru yere ulaştırma yeteneği ve potansiyeline sahip teknolojik insansız hava araçlarıdır (Yoo vd., 2018). Drone'lar, perakende şirketleri tarafından geleneksel taşımacılığa umut verici bir alternatif olarak teslimat hizmetlerinde yoğun bir şekilde tanitılan otonom araçlardır (Gramatikov, Kitanovski, Mishkovski ve Jovanovik, 2019). Drone'lar, perakende şirketlerinin hizmetlerini iyleştirmenin bir yolu olarak, ürün teslimatında yenilikçi ve çarpıcı gelişmelerden biri olarak görülmektedir (Kaoy, Lesmini ve Budiman, 2020).

Perakendede ürün teslimatı için drone kullanımı, özellikle Amazon ve Walmart gibi önde gelen perakende şirketleri tarafından maliyetleri düşürmek, teslimat hizmet kalitesini artırmak ve müşteri beklentilerini karşılamak için drone ile ürün teslimat hizmetinin tanıtılmasıyla birlikte popülerlik kazanmıştır (Macrina, Pugliese, Guerriero ve Laporte, 2020; Yoo vd., 2018). Bununla birlikte, tüketiciler tarafından ürün teslimat hizmetleri için kullanılan drone teknolojisi bilişsel olarak kabul edilirse, bu teknolojinin perakendeciler ve tüketiciler arasındaki ilişki için genel değer zinciri üzerinde beklenen şekilde yüksek bir etkiye sahip olması beklenmektedir (Ramadan vd., 2017). Bu bağlamda perakendecilikte drone ile ürün teslimatının ilgili boyutlar itibari ile tüketicilerin davranışsal niyetlerine etkisinin olup olmadığının araştırılması, tüketici araştırmalarında önemli bir yer tutmaktadır.

\section{Davranışsal niyetler}

Davranışsal niyetler, belirli bir davranışsal eylemleri gerçekleştirmenin öncülleri olarak kabul edilir. (Ajzen ve Fishbein, 1969). Davranışsal niyet, bir kişinin gelecekteki bazı belirli davranışları gerçekleştirmek ya da gerçekleştirmemek için bilinçli planlar formüle etmesidir (Warshaw ve Davis, 1985). Teknoloji bilgi araştırmalarında drone ile ürün teslimatı yapmak için drone kullanma niyeti, tüketicilerde incelenen davranışsal niyettir (Hwang vd., 2019b; Hwang vd., 2020).

Tüketicilerin belirli bir sistemi kullanmaya yönelik davranışsal niyetleri olmaktadır (Davis, Bagozzi ve Warshaw, 1989). Tüketicilerin hedef sistemleri kullanmalarına ilişkin davranışsal niyetleri açısından cinsiyetler arasında (Kim ve Forsythe, 2008) ve jenerasyonlar arasında (Köse ve Yengin, 2018) anlamlı bir farklılığın olmadığı görülmektedir. Bu bilgilere istinaden $\mathrm{H}_{1 a}, \mathrm{H}_{1 b}$ ve $\mathrm{H}_{1 c}$ hipotezleri geliştirilmiştir.

$H_{1 a}$ : Drone ile ürün teslimatı drone kullanma niyeti üzerinde olumlu ve anlamlı bir etkiye sahiptir. 
$\boldsymbol{H}_{1 b}$ : Drone kullanma niyeti açısından cinsiyetler arasinda anlamlı bir farklllı yoktur.

$H_{1 c}$ : Drone kullanma niyeti açısından jenerasyonlar arasında anlamlı bir farklılı yoktur.

\section{Algılanan yenilikçilik}

Yenilik, tüketicinin veya işletmenin bir fikri, uygulamayı veya nesneyi yeni olarak algılamasıdır (Rogers, 1983). Bu tanımlamaya göre; bir yenilik ancak tüketiciler veya işletmeler tarafından algılandığında var olmaktadır (Kim vd., 2021). Bilgisayarlaşmanın görülmesinden bu yana bilgi teknolojilerinde görülen yeniliklerin tüketiciler ve işletmeler tarafından kabul edilmesi, önemli bir araştırma alanıdır (Moore ve Benbasat, 1991).

Algılanan yenilikçilik, tüketicilerin drone ile ürün teslimatı gibi yeni bir ürün veya hizmetin önemli yenilik özelliklerine sahip olduğuna inanma derecesidir (Hwang vd., 2019b). Son zamanlarda, drone ile ürün teslimatına ilişkin tüketiciler tarafından algılanan yenilikçilik, akademik araştırmalarda büyük ilgi görmüştür (Kim vd., 2021). Tüketici açısından bakıldığında, drone ile ürün teslimatının algılanan yenilikçiliği, drone kullanmaya yönelik tutum üzerinde önemli bir etkiye sahiptir (Hwang vd., 2019b; Kim vd., 2021). Bu bilgiler ışı̆̆ında $\mathrm{H}_{2}$ hipotezi geliştirilmiştir.

$\mathrm{H}_{2}$ : Algllanan yenilikçilik, drone kullanmaya yönelik tutum üzerinde olumlu ve anlamlı bir etkiye sahiptir.

\section{Hızın göreceli avantajı}

Drone'lar, yol altyapısı ve trafik sıkışıklığı gibi yer engellerinden etkilenmedikleri için ürün teslimatı bakımından drone kullanmanın temel avantajı hızlı olarak teslimat yapmalarıdır (Yoo vd., 2018). Yapılan testlere göre; drone ile teslimat hızı, teslimat hızının kritik olduğu gıdalar için özellikle önemli olmaktadır (Park, Kim ve Suh, 2018). Drone'ları kullanarak, yiyeceklerin soğumasını veya bozulmasını önlemek için müşterilerin istedikleri yerde ve zamanda daha hızlı teslimat bakımından gereken esnekliği sunmak mümkündür (Park vd., 2018; Yoo vd., 2018).

Yapılan deneysel çalışmada, şarj ve hava koşulları göz önünde bulundurularak drone ile teslimat için esnek bir hizmet bileşimi algoritması geliştirilmiştir (Shahzaad, Bouguettaya, Mistry ve Neiat, 2021). Drone ile ürün teslimatı, teslimat sürecine alternatif bir çözüm sunarak, teslimat rotalarından ve zamandan tasarruf sağlamakta hatta tedarik zincirine esneklik kazandırmaktadır (Hernández, Martínez ve Saucedo, 2020).

Drone ile ürün teslimat hızının göreceli avantajı, tüketici araştırmalarında test edilmiştir. Tüketici açısından bakıldığında, drone ile ürün teslimat hızının göreceli avantajının, drone kullanmaya yönelik tutum üzerinde önemli bir etkisi olmaktadır (Yoo vd., 2018). Buna göre $\mathrm{H}_{3}$ hipotezi geliştirilmiştir.

\section{$\boldsymbol{H}_{3}$ : Hizın göreceli avantajı, drone kullanmaya yönelik tutum üzerinde olumlu ve anlamlı bir etkiye sahiptir.}

\section{Fonksiyonel motivasyon}

Fonksiyonel motivasyon, tüketicinin fayda elde etmek için drone ile ürün teslimat hizmetinin fonksiyonel performans beklentisi ile motive edilmesidir (Kapser ve Abdelrahman, 2020). Fonksiyonel motivasyon, tüketicinin drone ile ürün teslimatında fonksiyonel performanslar tarafından motive edilmesine, görev yönetimine ve başarının artırılmasına odaklanmasıyla ilgili bir boyuttur (Hwang vd., 2019a). Fonksiyonel olarak motive olmuş yenilikçi tüketiciler, performansı veya görevin yönetimini iyileştirmek, verimliliği artırmak ve tehdit edici koşullardan kaçınmak için yenilikleri kabul etmektedirler (Vandecasteele ve Geuens, 2010). Bu nedenle, drone ile ürün teslimatının tüketicilere sunduğu fonksiyonel motivasyonun, drone ile ürün teslimatı için genel imaj (Hwang vd., 2021) ve drone ile ürün teslimat hizmeti yeniliğinin kullanılması için davranışsal niyet (Kapser ve Abdelrahman, 2020) üzerinde önemli bir etkisi vardır.

Perakende sektöründe teslimat hizmetleri için ticari drone'ların kullanılmasının fonksiyonel faydası, bilgi teknolojisi araştırmalarında araştırmacıların dikkatini çekmiştir (Ramadan vd., 2017; Tom, 2020). Tüketici açısından bakıldığında, drone ile ürün teslimatının fonksiyonel motivasyonu, drone kullanmaya yönelik tutum üzerinde önemli bir etkiye sahiptir (Hwang vd., 2019a; Mathew vd., 2021; Ramadan vd., 2017). Bu bilgiler göz önüne alınarak $\mathrm{H}_{4}$ hipotezi geliştirilmiştir.

$\mathrm{H}_{4}$ : Fonksiyonel motivasyon, drone kullanmaya yönelik tutum üzerinde olumlu ve anlaml bir etkiye sahiptir.

\section{Hedonik motivasyon}

Hedonik motivasyon, drone ile ürün teslimat hizmetini kullanmaktan elde edilen eğlence veya zevktir (Kapser ve Abdelrahman, 2020). Hedonik motivasyon, tüketicinin drone ile ürün teslimatında duygusal veya duyusal uyarım ve tatmin tarafından motive olması ile ilgili bir boyuttur (Hwang vd., 2019a). Hedonik olarak motive olmuş yenilikçi tüketiciler; heyecanlanmak, sevinç ve tatmin duygularını 
yaşamak istedikleri için yenilikleri kabul etmektedirler (Vandecasteele ve Geuens, 2010). Dolayısıyla işletmelerin tüketicilere üst düzey hedonik deneyimler sunması, drone ile ürün teslimatını kabul etmede etkili olmaktadır (Hwang vd., 2021). Ayrıca, drone ile ürün teslimatının tüketicilere sunduğu hedonik faydaların drone ile ürün teslimatı için genel imaj (Hwang ve Kim, 2021) ve drone ile ürün teslimat hizmet yeniliğinin kullanılması için davranışsal niyet (Kapser ve Abdelrahman, 2020) üzerinde önemli bir etkisi vardır.

Drone ile ürün teslimatının hedonik motivasyonu, tüketici davranışlarını tanımlamak için bilgi teknolojisi araştırmalarında araştırmacıların dikkatini çeken bir araştırma konusudur (Kapser ve Abdelrahman, 2020; Tom, 2020). Tüketici açısından bakıldığında, drone ile ürün teslimatının hedonik motivasyonu, drone kullanmaya yönelik tutum üzerinde önemli bir etkiye sahiptir (Hwang vd., 2019a; Hwang vd., 2021). Bu bağlamda $\mathrm{H}_{5}$ hipotezi geliştirilmiştir.

$H_{5}$ : Hedonik motivasyon, drone kullanmaya yönelik tutum üzerinde olumlu ve anlamlı bir etkiye sahiptir.

\section{Algılanan güven}

Toplumsal açıdan kamu güvenliği, teknolojik açıdan çarpışmanın önlenmesi, lojistik açıdan sigortalama, hizmet açısından kötü hava koşullarında teslimat ve son olarak yasal ve çevresel açıdan doğru izinler ve düzenlemeler, drone ile ürün teslimatı hizmetinin performansı için önemli faktörlerdir (Jaramillo, Shih ve Cheng, 2019). Bu nedenle, tüketicinin drone ile ürün teslimatına olan güven algis1, drone ile ürün teslimatına katılma niyetleri üzerinde önemli bir etkiye sahiptir (Mittendorf, Franzmann ve Ostermann, 2017). Tüketici drone ile ürün teslimatına güvendiğinde, drone ile ürün teslimatını kullanmayı kabul etmektedir (Kaoy vd., 2020). Tüketici drone ile ürün teslimatının arkasındaki teknolojiye güvenmiyorsa, tüketicinin drone ile ürün teslimatını kullanması pek mümkün değildir (Mittendorf vd., 2017; Tom, 2020).

Güven, hedef bilgi sisteminin kullanılmasının arkasındaki nedeni açıklamak için bilgi teknolojisi araştırmalarında araştırılması gereken önemli bir konudur (Kaoy vd., 2020; Mittendorf vd., 2017; Tom, 2020). Hedef bilgi sisteminin algilanan güveni, hedef bilgi sistemini kullanmaya yönelik tutum ile önemli bir ilişkiye sahip olmaktadır (Wu ve Ke, 2015). Buna göre; tüketici açısından bakıldığında, drone ile ürün teslimatının algılanan güveni, drone kullanmaya yönelik tutum üzerinde önemli bir etkiye sahip olması beklenmektedir. Buna göre $\mathrm{H}_{6}$ hipotezi geliştirilmiştir.

$H_{6}$ : Algzlanan güven, drone kullanmaya yönelik tutum üzerinde olumlu ve anlamlı bir etkiye sahiptir.

\section{Problem farkındalı̆̆ı}

Problem farkındalığı, motosikletler veya arabalar gibi geleneksel teslimat yöntemlerinin aksine drone ile ürün teslimatının daha az çevresel soruna neden olan, daha yeşil bir teslimat yöntemi olduğunu bilmek ve inanmakla ilgilidir (Kim ve Hwang, 2020). Benzinle çalışan ve dolayısıyla çevre kirliliğine neden olan ürün teslimat hizmetlerinde kullanılan motosikletlerin ve arabaların aksine, ürün teslimat hizmetlerinde kullanılan drone'lar elektrikle çalıştıkları için çevrenin korunmasında büyük role sahiptirler (Hwang vd., 2019a). Bu nedenle, motosiklet ve araba gibi geleneksel teslimat araçlarının çevresel etkileri ile karşılaştırıldığında, yeni bir teslimat aracı olarak drone'ların çevresel etkileri, araştırmacıların ilgisini çeken önemli bir araştırma konusudur (Park vd., 2018).

Çevreci eylemlerde bulunma zorunluluğu duygusu, tüketicilerin davranışsal niyetleri üzerinde önemli bir etkiye sahiptir (Hwang vd., 2020). Çevre kirliliği sorunları ciddileştikçe tüketicilerin drone ile ürün teslimat hizmetini kullanma gibi yeşil tüketim davranışları sergiledikleri görülmektedir (Hwang ve Kim, 2019). Çünkü, tüketiciler, motosikletlerin ve arabaların egzoz gazlarının ciddi düzeyde hava kirliliğine neden olduğunun farkındadır (Kim ve Hwang, 2020). Tüketici açısından bakıldığında, motosikletler veya arabalar gibi mevcut teslimat yöntemleriyle ürün teslimatının çevreye olan zararları gibi problemlerden dolayı drone ile ürün teslimatı, drone kullanmaya yönelik tutum üzerinde önemli bir etkiye sahiptir (Hwang ve Kim, 2019; Kim ve Hwang, 2020). Buna göre $\mathrm{H}_{7}$ hipotezi geliştirilmiştir.

$H_{7}$ : Problem farkındalı̆̆l, drone kullanmaya yönelik tutum üzerinde olumlu ve anlamlı bir etkiye sahiptir.

\section{Algılanan risk}

Algılanan risk, drone ile ürün teslimat hizmeti yeniliğini kullanarak istenen sonuçların elde edilip edilmeyeceğine dair bir belirsizlik olduğuna inanma derecesidir (Mittendorf vd., 2017). Algilanan risk, tüketicinin drone ile ürün teslimatı kullanımından kaynaklanan olası belirsizliğe ve hoş olmayan sonuçlara ilişkin algısıdır (Ramadan vd., 2017). Tüketici, birçok yeni teknolojik hizmetin doğası gereği, drone ile ürün teslimat hizmeti yeniliğinin kullanımını riskli görebilmektedir (Kapser ve Abdelrahman, 2020). Bu nedenle, drone'lar perakendeciler için gelecek vaat eden bir teknoloji olsa da perakendecilerin, 
tüketicinin drone ile ürün teslimatına ilişkin risk algısını dikkate almaları ve aynı zamanda bu risk algısını ortadan kaldırmak için çözüm üretmeleri gerekmektedir (Khan vd., 2019).

Ekonomik olarak avantajlı ve en az riskli olarak algılanan yenilikler, daha huzlı kabul görmektedir (Rogers, 1983). Bu açıdan algılanan risk, tüketicinin drone ile ürün teslimat hizmeti yeniliğini kullanma niyetini etkileyen önemli bir faktördür (Mittendorf vd., 2017). Bilgi teknolojisi araştırmalarında tüketici bakış açısıyla algılanan riskin araştırılması araştırmacıların dikkatini çekmektedir (Hwang ve Choe, 2019; Mittendorf vd., 2017). Tüketici açısından bakıldığında, drone ile ürün teslimatının algılanan riski, drone kullanmaya yönelik tutum üzerinde önemli bir etkiye sahiptir (Ramadan vd., 2017; Yoo vd., 2018). Bu bilgilere istinaden $\mathrm{H}_{8}$ hipotezi geliştirilmiştir.

$H_{8}$ : Algilanan risk, drone kullanmaya yönelik tutum üzerinde olumsuz ve anlaml bir etkiye sahiptir.

\section{Tutum}

Tutum, bir kişinin belirli bir davranışı gerçekleştirmeye yönelik olumlu veya olumsuz tutarlı tepkisini temsil etmektedir (Fishbein ve Ajzen, 1975). Bir davranışa yönelik tutum, o davranışa ilişkin dikkat çekici faktörler tarafından belirlenmektedir (Ajzen, 1985). Bireylerin belirli eylemlere yönelik davranışsal niyetlerini tahmin ederken, bireylerin bu eylemlere yönelik tutumlarını ve bireylerin bu tutumlarını etkileyen faktörleri göz önünde bulundurmak gerekmektedir (Ajzen ve Fishbein, 1969). Bundan dolayı, bu çalışmada drone ile ürün teslimatı yapma niyetiyle ilgili olarak algılanan yenilikçilik, hızın göreceli avantajı, fonksiyonel motivasyon, hedonik motivasyon, algılanan güven, problem farkındalığı ve algılanan risk, drone kullanmaya yönelik tutumun önemli belirleyicileri olarak kabul edilen faktörlerdir.

Bilgisayar tabanlı araçların kullanımına yönelik tutum, bu araçların kullanımına ilişkin davranışsal niyetlerin önemli bir belirleyicisidir (Davis vd., 1989). Tüketici bakış açısından bakıldığında, drone kullanmaya yönelik tutum, drone kullanmaya yönelik davranışsal niyetler üzerinde önemli bir etkiye sahiptir (Hwang ve Kim, 2019; Hwang vd., 2019a, 2019b; Hwang vd., 2021; Kim vd., 2021; Mathew vd., 2021; Ramadan vd., 2017). Bu bağlamda $\mathrm{H}_{9}$ hipotezi geliştirilmiştir.

H9: Drone kullanmaya yönelik tutum, drone kullanma niyeti üzerinde olumlu ve anlaml bir etkiye sahiptir.

\section{Yöntem}

\section{Araştırmanın modeli/hipotezleri}

Mevcut çalışmanın araştırma modeli, algılanan yenilikçilik, hızın göreceli avantajı, fonksiyonel motivasyon, hedonik motivasyon, algılanan güven, problem farkındalığı, algılanan risk, drone kullanmaya yönelik tutum ve drone kullanma niyeti ve bunların aralarındaki ilişkileri üzerine kurulmuştur. Aynı zamanda drone ile ürün teslimatı, cinsiyet ve jenerasyon araştırmanın kontrol değişkenleridir. Araştırma Modeli aşağıda Şekil 1'de verilmiştir.

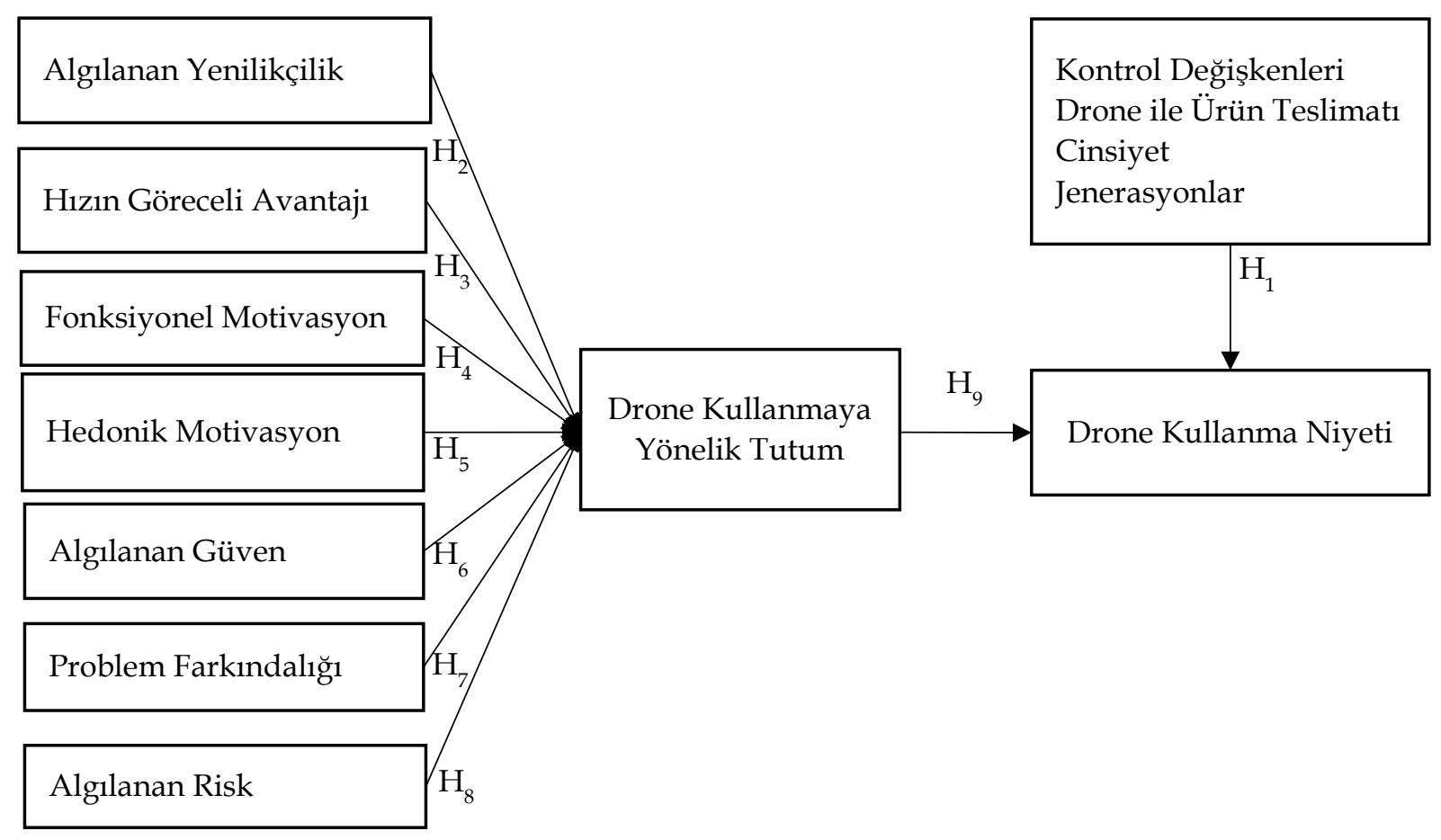

Şekil 1. Araştırma Modeli 


\section{Evren ve örneklem}

Çalışmanın evrenini Türkiye İstatistik Kurumu 2021 verilerine göre, 83 milyon 614 bin 362 kişi olan Türkiye nüfusu oluşturmaktadır. Online olarak hazırlanan anket formunun linki sosyal medya uygulamalarıyla paylaşılmıştır. 409 anket formu elde edilmiştir. Hatalı 5 anket formu çıarılarak 404 anket formunun SPSS 25 paket programına veri girişi yapılmıştır. Araştırma modelinde yer alan 9 değişkene göre, 404 kişilik örneklem büyüklüğü, Stevens (1996, s. 72)'ın bağımsız değişken başına 15 denek ile Tabachnick ve Fidell $(2007$, s. 123 )'in $\mathrm{n}>50+8 \mathrm{M}$ ( $\mathrm{M}=$ bağımsız değişken sayısı) minimum örneklem büyüklüğü ölçütlerini sağlamaktadır. Ayrıca Hair, Black, William, Babin ve Anderson (2009, s. 329) ölçek maddelerinin en az 10 katı kadar örnek toplanması gerektiğini belirtmişlerdir. Çalışmada 27 ölçek maddesi kullanıldığı göz önüne alındığında 404>270 hesabına göre gereken örneklem sayısından fazlasına ulaşılmıştır. Krejcie ve Morgan (1970) ise \%95 güven düzeyine ulaşılabilmesi için aşağıdaki formülü ileri sürmüşlerdir.

$$
\begin{aligned}
& n=\frac{x^{2} * \mathrm{~N} * \mathrm{P} *(1-\mathrm{P})}{d^{2} *(\mathrm{~N}-1)+x^{2} * P *(1-\mathrm{P})} \\
& n=\frac{3.841 * 83614362 * 0.5 *(1-0.5)}{(0.05)^{2} *(83614362-1)+3.841 * 0.5 *(1-0.5)} \\
& n=384.098240158
\end{aligned}
$$

n: İstenilen güven düzeyi için yeterli örneklem sayısı

$\mathrm{x}^{2}$ : İstenen güven düzeyinde 1 serbestlik derecesi için ki-karenin tablo değeri

\section{N: Evren}

P: Popülasyon oranı (maksimum örneklem büyüklüğünü sağlayacağı için 0.5 olduğu varsayılmıştır).

d: 0.05 oranı olarak ifade edilen doğruluk derecesi.

Kullanılan formüle ve 83 milyon 614 bin 362 kişilik Türkiye nüfusuna göre, 404 kişilik örneklemin (404>384) \%95 üzerinde güven düzeyi vardır (Krejcie ve Morgan, 1970). Sonuç olarak kolayda örnekleme yöntemiyle ulaşılan 404 kişi, çalışmanın örneklemini oluşturmaktadır.

\section{Veri toplama aracı}

$\mathrm{Bu}$ çalışma için verilerin toplanmasında online anket ve deney yöntemi kullanılmıştır. Katılımcılar, drone ile ürün teslimatı ile ilgili bir video içeriği izledikten sonra kendilerine yöneltilen anket sorularını yanıtlamışlardır. Video içeriği, müşterinin mobil uygulamayı kullanarak e-perakendede ürün siparişini vermesi, ürün siparişinin hazırlanıp paketlenmesi ve drone ile ürün paketinin müşterinin önceden belirlenmiş adresine otuz dakika gibi kısa bir süre içinde teslimatının yapılmasına yöneliktir. Video içeriğinde drone markasının ismi, mobil uygulamaya ait marka ismi, ürün marka isimleri ve eperakendenin marka ismi gösterilmediği için bu çalışmanın araştırma konusu belirli bir markaya veya markalara yönelik değildir.

Veri toplamak için anket yöntemi ve deney kullanılacak ise, etik kurulu izninin alınması gerekmektedir. Etik kurulu izninin alınması için Van Yüzüncü Yıl Üniversitesi Sosyal ve Beşerî Bilimleri Yayın Etik Kurulu'na başvurulmuştur. 2021/10-05 sayılı ve 10/08/2021 tarihli onay belgesi alınmıştır.

\section{Ölçekler ve ölçek soruları}

Mevcut çalışmalardan yararlanılarak bu çalışma için hazırlanan ölçek soruları kaynaklarıyla birlikte aşağıda Tablo 1'de verilmiştir. 
Tablo 1: Çalışma Ölçek Soruları ve Ölçek Soruları İçin Faydalanılan Kaynaklar

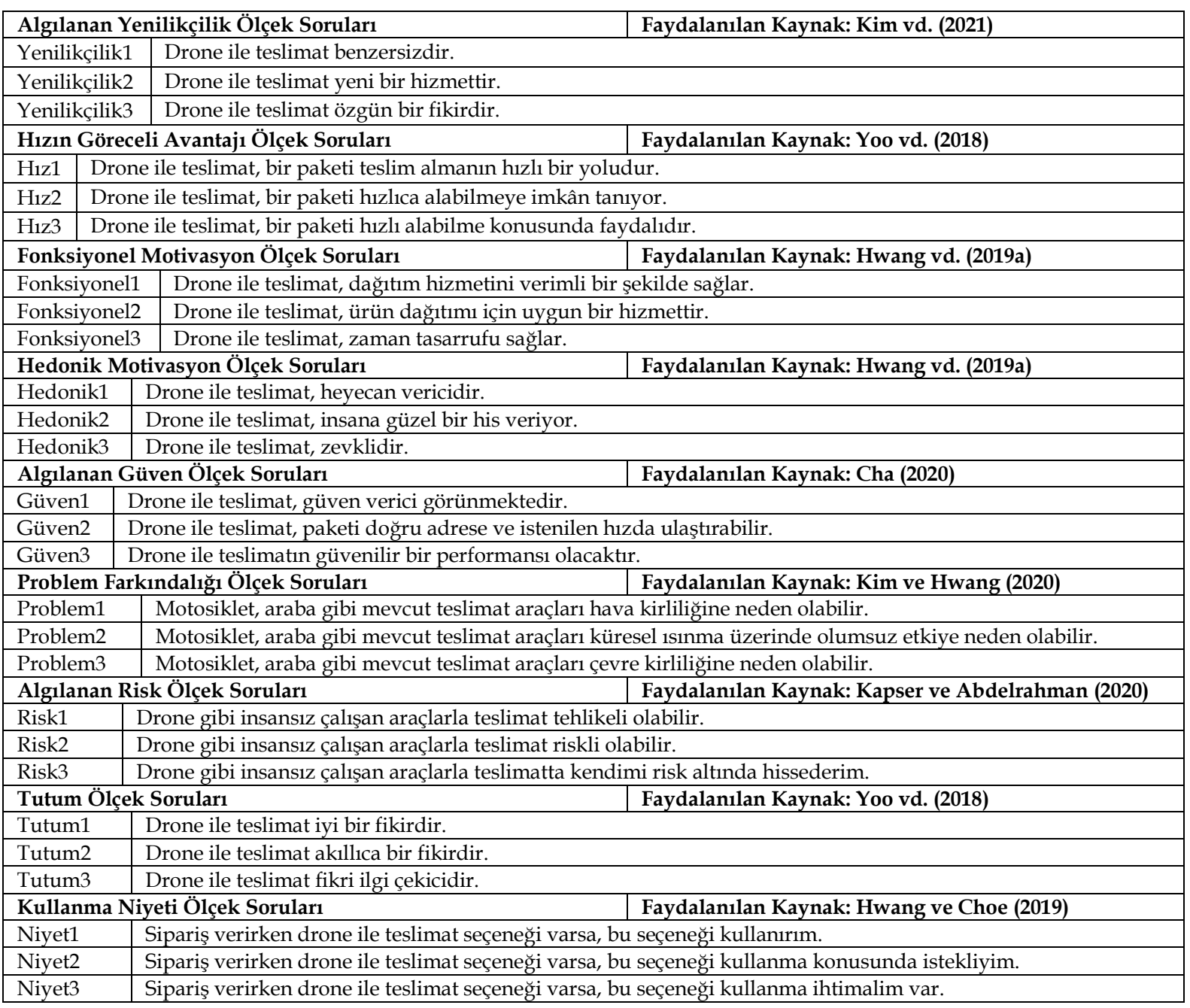

\section{Verilerin analizi}

Çalışma hipotezlerinin test edilmesi için istatistiksel analizler kullanılmıştır. Tek yönlü varyans analizi, tek örneklem t-testi ve bağımsız örneklemler t-testi, kontrol değişkeleri için farklılıkların test edilmesinde kullanılmıştır. Basit lineer regresyon analizi, bir bağımsız değişkenin bağımlı değişken üzerindeki etkisinin test edilmesinde kullanılmıştır.

\section{Bulgular}

Katılımcıların demografik özellikleri Tablo 2'de verilmiştir.

Tablo 2: Katılımcıların Demografik Özellikleri

\begin{tabular}{|c|c|c|c|}
\hline Demografik Özellikler & Grup & Frekans (f) & Yüzde (\%) \\
\hline \multirow{2}{*}{ Cinsiyet } & Kadın & 114 & 28,2 \\
\hline & Erkek & 290 & 71,8 \\
\hline \multicolumn{2}{|r|}{ Toplam } & 404 & 100 \\
\hline \multirow{4}{*}{ Yaş } & 9-25 yaş arası (1996-2012; $Z$ jenerasyon) & 90 & 22,3 \\
\hline & 26-40 yaş arası (1981-1995; $\mathrm{Y}$ jenerasyon) & 228 & 56,4 \\
\hline & 41-56 yaş arası (1965-1980; X jenerasyon) & 78 & 19,3 \\
\hline & 57-75 yaş arası (1946-1964; Baby Boomer jenerasyon) & 8 & 2,0 \\
\hline \multicolumn{2}{|r|}{ Toplam } & 404 & 100 \\
\hline \multirow{4}{*}{ Eğitim Durumu } & İlkokul mezunu & 6 & 1,5 \\
\hline & Ortaokul mezunu & 13 & 3,2 \\
\hline & Lise mezunu & 75 & 18,6 \\
\hline & Üniversite mezunu & 310 & 76,7 \\
\hline \multicolumn{2}{|r|}{ Toplam } & 404 & 100 \\
\hline \multirow{4}{*}{ Aylık Gelir } & $0-2500$ TL arasi & 99 & 24,5 \\
\hline & $2501-5000 \mathrm{TL}$ aras1 & 103 & 25,5 \\
\hline & 5001-7500 TL aras1 & 116 & 28,7 \\
\hline & 7500 TL üstü & 86 & 21,3 \\
\hline \multicolumn{2}{|r|}{ Toplam } & 404 & 100 \\
\hline
\end{tabular}


Toplam katılımcıların ( $\mathrm{n}=404 ; \% 100)$ çoğunluğunu; erkek ( $\mathrm{n}=290 ; \% 71,8), 26-40$ yaş arası $\mathrm{Y}$ jenerasyonu $(\mathrm{n}=228 ; \% 56,4)$, üniversite mezunu $(\mathrm{n}=310 ; \% 76,7)$ ve aylık gelirleri 5001-7500 TL arası değişen $(\mathrm{n}=116$; $\% 28,7)$ katılımcılar oluşturmaktadır.

Faktör ve güvenilirlik analizi sonuçları Tablo 3'te verilmiştir.

Tablo 3: Faktör ve Güvenilirlik Analizi Sonuçları

\begin{tabular}{|c|c|c|c|c|}
\hline Faktör İsmi & Faktör İfadeleri & Faktör Yükü & Açıklanan Varyans \% & Güvenilirlik \\
\hline \multirow{3}{*}{ Kullanma Niyeti } & Niyet2 & ,938 & \multirow{3}{*}{50,089} & \multirow{3}{*}{943} \\
\hline & Niyet3 & ,902 & & \\
\hline & Niyet1 & 890 & & \\
\hline \multirow{3}{*}{ Algılanan Güven } & Güven2 & 900 & \multirow{3}{*}{11,185} & \multirow{3}{*}{,909 } \\
\hline & Güven1 & 893 & & \\
\hline & Güven3 & 875 & & \\
\hline \multirow{3}{*}{ Hızın Göreceli Avantajı } & Hiz2 & ,926 & \multirow{3}{*}{7,390} & \multirow{3}{*}{,937 } \\
\hline & Hiz1 & ,914 & & \\
\hline & Hiz3 & ,734 & & \\
\hline \multirow{3}{*}{ Problem Farkındalığı } & Problem1 & ,939 & \multirow{3}{*}{4,636} & \multirow{3}{*}{,938 } \\
\hline & Problem2 & 935 & & \\
\hline & Problem3 & ,920 & & \\
\hline \multirow{3}{*}{ Algılanan Risk } & Risk2 & ,950 & \multirow{3}{*}{3,550} & \multirow{3}{*}{921} \\
\hline & Risk1 & ,943 & & \\
\hline & Risk3 & 889 & & \\
\hline \multirow{3}{*}{ Hedonik Motivasyon } & Hedonik1 & 887 & \multirow{3}{*}{3,143} & \multirow{3}{*}{914} \\
\hline & Hedonik3 & 828 & & \\
\hline & Hedonik2 & 796 & & \\
\hline \multirow{3}{*}{ Algılanan Yenilikçilik } & Yenilikçi2 & 807 & \multirow{3}{*}{2,221} & \multirow{3}{*}{,802 } \\
\hline & Yenilikçi3 & 729 & & \\
\hline & Yenilikçi1 &, 516 & & \\
\hline \multirow{3}{*}{ Tutum } & Tutum3 & 767 & \multirow{3}{*}{2,174} & \multirow{3}{*}{,886 } \\
\hline & Tutum2 & ,742 & & \\
\hline & Tutum1 & 663 & & \\
\hline \multirow{3}{*}{ Fonksiyonel Motivasyon } & Fonksiyonel1 & 584 & \multirow{3}{*}{1,813} & \multirow{3}{*}{,890 } \\
\hline & Fonksiyonel2 & 549 & & \\
\hline & Fonksiyonel3 & 511 & & \\
\hline \multicolumn{2}{|c|}{ Açıklanan Toplam Varyans \% } & 86,202 & & \\
\hline \multicolumn{3}{|c|}{ Kaiser-Meyer-Olkin (KMO) Örnekleme Yeterliliği Ölçütü } & \begin{tabular}{l|l|} 
&, 938 \\
\end{tabular} & \\
\hline \multirow{3}{*}{\multicolumn{3}{|c|}{ Bartlett's Küresellik Testi }} & Yaklaşık Ki-Kare & 10941,701 \\
\hline & & & df & 351 \\
\hline & & & $\mathbf{p}$ & ,000 \\
\hline
\end{tabular}

KMO değeri $\geq 0,50$ ve $p$ değeri $\leq 0,05$ olduğundan veri seti, faktör analizine uygundur (Field, 2000). Buna ek olarak, örneklem sayısına göre değişebilen her bir faktör yükünün $\geq 0,30$ (Stevens, 2002), $\geq 0,32$ (Tabachnick ve Fidell, 2013), 0,30 ile 0,40 arası (Coombs ve Schroeder, 1988; Dunteman, 1989), $\geq 0,40$ (Field, 2000) veya $\geq 0,50$ (Hair vd., 2009) çıkması farklı yazarlar tarafından kabul edilen değerlerdir. Sosyal bilimlerde kabul edildiği şekilde her bir faktör yükü $\geq 0,50$ çıkmıştır (Hair vd., 2009). Dahası, açılanan toplam varyansın \%40 veya \%60 (Dunteman, 1989), \%52,03 (Henson ve Roberts, 2006: s. 402), \%60 (Hair vd., 2009, s. 109), \%75 veya daha fazlası (Stevens, 1996: s. 364), \%75, \%80 veya \%85 (Gorsuch, 1983, s. 165) çıkması faklı yazarlar tarafından kabul edilen değerlerdir. Açıklanan toplam varyansın \%86,202 çıkmış olması kabul edilen bir değerdir (Gorsuch, 1983, s. 165). Son olarak, faktör boyutunda faktör ifade sayısı az olduğunda güvenilirlik değerinin $\geq 0,60$ çıkması kabul edilen bir değerdir (Sipahi vd., 2008: s. 89). Bunun birlikte, faktör boyutunun güvenilirlik değeri $\geq 0,70$ çıktığında faktör boyutu güvenilir kabul edilmelidir (Nunnally, 1978). Faktör boyutunun güvenilirlik değeri $0,80 \leq \alpha<1,00$ aralığında çıktığında ise, faktör boyutu yüksek düzeyde güvenilir kabul edilmelidir (Kayış, 2005). Bu doğrultuda her bir faktör boyutunun güvenilirlik değeri $0,80 \leq a<1,00$ aralığında çıktığından bu faktör boyutların her biri yüksek düzeyde güvenilirdir (Kayış, 2005).

Tüm katılımcıların drone ile ürün teslimatını kullanmaya yönelik davranışsal niyetlerinin anlaşılması amacıyla, herhangi bir demografik fark gözetilmeden bütün veriler birlikte ele alınmıştır. Bunun için uygun istatistiki analiz olan tek örneklem t-testi uygulanmış elde edilen bulgular Tablo 4 'te verilmiştir.

Tablo 4: Tek Örneklem t-Testi Sonuçları

\begin{tabular}{|l|l|c|c|c|c|c|c|c|}
\hline \multirow{2}{*}{ Bağımsız Değişken } & \multirow{2}{*}{ Bağımı Değişken } & \multicolumn{5}{|c|}{ Test Value: 3} \\
\cline { 3 - 8 } & & Hipotez & $\overline{\mathbf{x}}$ & $\mathbf{S d}$ & $\mathbf{t}$ & $\mathbf{P}$ & Sonuç \\
\hline Drone ile Ürün Teslimatı & Davranışsal Niyet & $\mathrm{H}_{1 \mathrm{a}}$ & 3,89 & 403 & 14,519 & 0,000 & Kabul \\
\hline
\end{tabular}


Drone ile ürün teslimatının, tüketicilerin drone ile teslimatı alışverişte kullanma davranışsal niyetleri üzerindeki etkisine yönelik olumlu ve anlamlı bir farklılaşmanın olduğu sonucuna ulaşılmıştır $\left(t_{403}\right.$ $=14,519 ; \mathrm{p}<0,05)$.

Bağımsız örneklemler t-testi sonuçları Tablo 5'te verilmiştir.

Tablo 5: Bağımsız Örneklemler t-Testi Sonuçları

\begin{tabular}{|c|c|c|c|c|c|c|c|c|}
\hline Grup & Hipotez & $\mathbf{n}$ & $\mathbf{x}$ & Ss & Sd & t & p & Sonuç \\
\cline { 1 - 9 } Kadın & \multirow{2}{*}{$\mathrm{H}_{1 \mathrm{~b}}$} & 114 & 3,87 & 1,14 & \multirow{2}{*}{402} & \multirow{2}{*}{, 286} & \multirow{2}{*}{, 775} & \multirow{2}{*}{ Kabul } \\
\cline { 1 - 6 } & & 290 & 3,90 & 1,27 & &
\end{tabular}

Tüketicilerin drone ile ürün teslimatını alışverişte kullanmaya yönelik davranışsal niyetlerinde cinsiyetler arasinda anlamlı bir farklılık yoktur $\left(\mathrm{t}_{402}=-, 286 ; \mathrm{p}>0,05\right)$.

Bağımsız gruplar için tek yönlü varyans (anova) analizi sonuçları Tablo 6'da verilmiştir.

Tablo 6: Bağımsız Gruplar İçin Tek Yönlü Varyans (Anova) Analizi Sonuçları

\begin{tabular}{|c|c|c|c|c|c|c|c|}
\hline $\begin{array}{c}\text { Varyansın } \\
\text { Kaynağı }\end{array}$ & Hipotez & $\begin{array}{c}\text { Kareler } \\
\text { Toplamı }\end{array}$ & Sd & $\begin{array}{c}\text { Kareler } \\
\text { Ortalaması }\end{array}$ & $\mathbf{F}$ & $\mathrm{p}$ & Sonuç \\
\hline Gruplararas1 & \multirow{3}{*}{$\mathrm{H}_{1 \mathrm{c}}$} & 7,755 & 2 & 3,877 & \multirow{3}{*}{2,568} & \multirow{3}{*}{,078 } & \multirow{3}{*}{ Kabul } \\
\hline Gruplar içi & & 593,344 & 393 & 1,510 & & & \\
\hline Toplam & & 601,098 & 395 & 5,387 & & & \\
\hline
\end{tabular}

Tüketicilerin drone ile ürün teslimatını alışverişte kullanmaya yönelik davranışsal niyetlerinde $X, Y$ ve $\mathrm{Z}$ jenerasyonları arasında anlamlı bir farklılık yoktur $\left(\mathrm{F}_{(2,393)}=2,568 ; \mathrm{p}>0,05\right)$. 57-75 yaş arası (Baby Boomers jenerasyon) katılımcılar sadece 8 kişi olduğundan, bu yaş grubu (jenerasyon) analize dâhil edilmemiştir

Basit lineer regresyon analizi sonuçları Tablo 7'de verilmiştir.

Tablo 7: Basit Lineer Regresyon Analizi Sonuçları

\begin{tabular}{|l|l|c|c|c|c|c|c|c|}
\hline \multicolumn{1}{|c|}{ Bağımsız Değişken } & \multicolumn{1}{|c|}{ Bağımlı Değişken } & Hipotez & $\mathbf{R}^{2}$ & $\mathbf{F}$ & $\boldsymbol{\beta}$ & $\mathbf{t}$ & $\mathbf{p}$ & Sonuç \\
\hline Algılanan Yenilikçilik & $\begin{array}{l}\text { Drone Kullanmaya Yönelik } \\
\text { Tutum }\end{array}$ & $\mathrm{H}_{2}$ &, 464 & 347,406 &, 681 & 18,639 &, 000 & Kabul \\
\hline Hızın Göreceli Avantajı & $\begin{array}{l}\text { Drone Kullanmaya Yönelik } \\
\text { Tutum }\end{array}$ & $\mathrm{H}_{3}$ &, 482 & 373,338 &, 694 & 19,322 &, 000 & Kabul \\
\hline Fonksiyonel Motivasyon & $\begin{array}{l}\text { Drone Kullanmaya Yönelik } \\
\text { Tutum }\end{array}$ & $\mathrm{H}_{4}$ &, 548 & 487,509 &, 740 & 22,080 &, 000 & Kabul \\
\hline Hedonik Motivasyon & $\begin{array}{l}\text { Drone Kullanmaya Yönelik } \\
\text { Tutum }\end{array}$ & $\mathrm{H}_{5}$ &, 481 & 372,245 &, 693 & 19,294 &, 000 & Kabul \\
\hline Algılanan Güven & $\begin{array}{l}\text { Drone Kullanmaya Yönelik } \\
\text { Tutum }\end{array}$ & $\mathrm{H}_{6}$ &, 452 & 331,544 &, 672 & 18,208 &, 000 & Kabul \\
\hline Problem Farkındalığ1 & $\begin{array}{l}\text { Drone Kullanmaya Yönelik } \\
\text { Tutum }\end{array}$ & $\mathrm{H}_{7}$ &, 090 & 39,607 &, 299 & 6,293 &, 000 & Kabul \\
\hline Algılanan Risk & $\begin{array}{l}\text { Drone Kullanmaya Yönelik } \\
\text { Tutum }\end{array}$ & $\mathrm{H}_{8}$ &, 003 & 1,045 &,- 051 & $-1,022$ &, 307 & Ret \\
\hline $\begin{array}{l}\text { Drone Kullanmaya } \\
\text { Yönelik Tutum }\end{array}$ & Drone Kullanma Niyeti & $\mathrm{H}_{9}$ &, 592 & 582,617 &, 769 & 24,137 &, 000 & Kabul \\
\hline
\end{tabular}

Algılanan yenilikçilik ( $\beta=, 681 ; p=, 000)$, hızın göreceli avantajı $(\beta=, 694 ; p=, 000)$, fonksiyonel motivasyon $(\beta=, 740 ; p=, 000)$, hedonik motivasyon $(\beta=, 693 ; p=, 000)$, algılanan güven $(\beta=, 672 ; p=, 000)$ ve problem farkındalığı $(\beta=, 299 ; p=, 000)$ drone kullanmaya yönelik tutum üzerinde olumlu ve anlamlı bir etkiye sahiptir. Ancak, $\beta$ kat sayısına göre; fonksiyonel motivasyon, drone kullanmaya yönelik tutum üzerinde en fazla olumlu ve anlamlı bir etkiye sahipken, problem farkındalığı, drone kullanmaya yönelik tutum üzerinde en az olumlu ve anlamlı bir etkiye sahiptir. Bununla birlikte, algılanan riskin drone kullanmaya yönelik tutum üzerindeki olumsuz etkisi anlamlı değildir $(\beta=-, 051 ; p=, 307)$. Son olarak, drone kullanmaya yönelik tutumun, drone kullanma niyeti üzerinde olumlu ve anlamlı bir etkisi vardır $(\beta=, 769 ; p=, 000)$.

\section{Tartışma ve sonuçlar}

Bu çalışmada algılanan yenilikçilik, hızın göreceli avantajı, fonksiyonel motivasyon, hedonik motivasyon, algılanan güven, problem farkındalığı ve algılanan riskin drone kullanmaya yönelik tutum üzerindeki etkisi; drone kullanmaya yönelik tutumun, drone kullanma niyeti üzerindeki etkisi; drone ile ürün teslimatının, ürün teslimatı için tüketicilerin alışverişte drone kullanmaya yönelik davranışsal niyetleri üzerindeki etkisi ve drone kullanmaya yönelik davranışsal niyetlerin cinsiyet ve jenerasyonlar açısından anlamalı olarak farklılık gösterip göstermediği incelenmiştir. 
Tek örneklem t-testi sonucunda, drone ile ürün teslimatının tüketicilerin alışverişte drone kullanma niyetleri üzerinde olumlu ve anlamlı bir etkisi vardır ( $\left.\mathrm{H}_{1 a} \mathrm{Kabul}\right)$. Bu sonuca göre; perakendecilikte drone ile ürün teslimat hizmeti, tüketicilerin davranışsal niyetleri üzerinde etkisi olduğu için umut vaat eden yeni bir teknolojik iş modelidir. Perakendecilikte drone kullanımı ile birlikte dağıtım maliyetlerinin düşeceği beklenmektedir. Elektrikle çalışan drone'lar, fosil yakıt kullanan araçların yakıtlarına yapılan masraflardan ya da kargo şirketlerine verilen ücretlerden çok daha uygun maliyetlerle dağıtım faaliyetlerini yerine getirebileceklerdir. Bu durumda drone kullanan işletmeler maliyet avantajı elde edecek ve dağıtım maliyetleri yüksek rakiplerine karşı etkin maliyetle rekabet avantajı elde edeceklerdir. Ayrıca kısa mesafelerde drone kullanımı ile trafik yoğunluğuna ya da uzun kargolama süreçlerine kıyasla hızlı teslim avantajı elde edilecek, drone kullanmayan rakiplere karşı rekabet üstünlüğü sağlanacak ve daha fazla müşteri tercihi ile birlikte müşteri sadakati elde edilecektir. Drone kullanma sonucu elde edilecek diğer bir önemli kazanım da fosil yakıtların aksine çevreye zarar verilmemesidir. $\mathrm{Bu}$ durum firmanın sosyal sorumluluğu bağlamında önemli olmakla beraber pazarlama iletişimi faaliyetleriyle daha fazla insanın bu durumdan haberdar olması, firmaya daha fazla ve sadık müşteri kazandırılmasına neden olacaktır.

Bağımsız örneklemler t-testi sonucunda, perakendecilikte tüketicilerin drone ile ürün teslimat hizmetini kullanma niyetlerinde cinsiyetler arasında anlamlı bir farklılık yoktur $\left(\mathrm{H}_{1 \mathrm{~b}} \mathrm{Kabul}\right)$. Benzer şekilde, bağımsız gruplar için tek yönlü varyans analizi sonucunda, perakendecilikte tüketicilerin drone ile ürün teslimatı hizmetini kullanma niyetlerinde $X, Y$ ve $Z$ jenerasyonları arasında anlamlı bir farklılık yoktur $\left(\mathrm{H}_{1 \mathrm{~b}} \mathrm{Kabul}\right)$. Bu sonuçlar, cinsiyet (erkek ve kadın) açısından (Kim ve Forsythe, 2008) ve jenerasyonlar (X, Y ve Z) açısından (Köse ve Yengin, 2018) tüketicilerin teknolojiyi kullanımlarının anlamlı bir farklılık göstermediği çalışma sonuçları ile benzerdir.

Basit lineer regresyon analizi sonucunda, algılanan yenilikçiliğin $\left(\mathrm{H}_{2} \mathrm{Kabul}\right)$, hızın göreceli avantajının $\left(\mathrm{H}_{3} \mathrm{Kabul}\right)$, fonksiyonel motivasyonun $\left(\mathrm{H}_{4} \mathrm{Kabul}\right)$, hedonik motivasyonun $\left(\mathrm{H}_{5} \mathrm{Kabul}\right)$, algilanan güvenin $\left(\mathrm{H}_{6} \mathrm{Kabul}\right)$ ve problem farkındalığının $\left(\mathrm{H}_{7} \mathrm{Kabul}\right)$ drone kullanmaya yönelik tutum üzerinde olumlu ve anlamlı bir etkisi olduğu görülmüştür. Bu sonuçlara göre; algılanan yenilikçiliğin (Bkz. Hwang vd., 2019b; Kim vd., 2021), hızın göreceli avantajının (Bkz. Yoo vd., 2018), fonksiyonel motivasyonun (Bkz. Hwang vd., 2019a; Mathew vd., 2021; Ramadan vd., 2017), hedonik motivasyonun (Bkz. Hwang vd., 2019a; Hwang vd., 2021), algılanan güvenin (Bkz. Wu ve Ke, 2015) ve problem farkındalığının (Bkz. Hwang ve Kim, 2019; Kim ve Hwang, 2020) drone kullanmaya yönelik tutum üzerinde olumlu ve anlamlı bir etkisinin olması ilgili literatürdeki çalışma sonuçları ile benzerlik göstermektedir. Bununla birlikte, basit lineer regresyon analizi sonucunda, algılanan riskin drone kullanmaya yönelik tutum üzerindeki olumsuz etkisinin anlamlı olmadığı görülmüştür $\left(\mathrm{H}_{8}\right.$ Ret). Dolayısıyla katılımcılar drone kullanmaya yönelik bir risk algılamamaktadır. Bu sonuç, ilgili literatürdeki yapılmış olan bazı çalışma sonuçları ile farklılık göstermektedir (Bkz. Ramadan vd., 2017; Yoo vd., 2018). Diğer taraftan, basit lineer regresyon analizi sonucunda, drone kullanmaya yönelik tutumun drone kullanma niyeti üzerinde olumlu ve anlamlı bir etkisi olduğu görülmüştür ( $\left.\mathrm{H}_{9} \mathrm{Kabul}\right)$. Bu sonuç, ilgili literatürdeki yapılmış olan pek çok çalışma sonucu ile benzerlik göstermektedir (Bkz. Hwang ve Kim, 2019; Hwang vd., 2019a, 2019b; Hwang vd., 2021; Kim vd., 2021; Mathew vd., 2021; Ramadan vd., 2017).

\section{Kisıtlamalar ve öneriler}

Bu çalışmada, online anket ve deney yöntemi kullanılarak zaman ve maliyet kısıtlamaları nedeniyle belirli sayıda katılımcıdan veri toplanmıştır. 404 kişilik örneklem büyüklügünün güven düzeyi yüksek olmasına rağmen, çalışmanın sonuçları katılımcıların demografik özellikleri dikkate alınarak değerlendirilmelidir. Erkek, Y jenerasyonu, üniversite mezunu ve aylık geliri 5001-7500 TL arasında değişen katılımcı sayısının fazla olduğu unutulmamalıdır.

Tüketici, perakendecilikte drone ile ürün teslimat hizmetine karşı olumlu bir tutum içindedir ve bu hizmeti kullanma niyetindedir. Ancak bu çalışmada tüketicilerin tutum ve niyetleri incelenirken, bu çalışmanın araştırma modelinin belirli faktörlere dayalı olarak geliştirildiğini belirtmekte fayda vardır.

Bu çalışmada, tüketici davranışlarını açıklamak için perakendecilik alanında tanıtılan drone ile ürün teslimatı konusu ele alınmaktadır. Ancak, kargolama ya da sağlık sektörü gibi alanlarda tanıtılan drone teknolojisi uygulamaları, ileride yapılacak başka çalışmalara örnek konu olarak seçilebillir.

Drone ile dağıtımın henüz yaygın şekilde uygulama alanı bulmaması nedeniyle insanların bu uygulamanın risklerini algılamada yeterli düşünsel kabiliyete erişemedikleri tahmin edilmektedir. Oysa ki ileride drone'ların yaygın kullanımı ile birlikte teknik aksaklıklardan dolayı insanlar üzerine düşüp insanlara zarar vermesi, hayvanlara, arabalara, eşyalara zarar verebilme olaylarının yaşanması, bu risklerin haberlere konu olmasıyla beraber insanların bu teslimat türüne karşı risk algılarının 
değişebileceği düşünülmektedir. Dolayısıyla drone'ların teslimatta yaygın kullnılmasıyla beraber çalışmada elde edilen sonucun aksine olacak sonuçlar elde edilebilir. İleride benzer çalışmaların yapılmasıyla insanlarda drone ile teslimata yönelik risk algısının değişip değişmediği anlaşılabilir.

Perakende sektöründe geleceğin dağıtım uygulamaları arasında yer alacak drone ile dağıtımın avantajları düşünüldüğünde firmalar açısından bu uygulamanın erken benimsenmesi önerilmektedir.

\section{Hakem Değerlendirmesi / Peer-review:}

Dış bağımsız

Externally peer-reviewed

\section{Çıkar Çatışması / Conflict of interests:}

Yazar(lar) çıkar çatışması bildirmemiştir.

The author(s) has (have) no conflict of interest to declare.

\section{Finansal Destek / Grant Support:}

Yazar(lar) bu çalışma için finansal destek almadığını beyan etmiştir.

The author(s) declared that this study has received no financial support.

\section{Etik Kurul Onayı / Ethics Committee Approval:}

Bu çalışma için etik kurul onayı, Van Yüzüncü Yıl Üniversitesi, Sosyal ve Beşeri Bilimleri Yayın Etik Kurulu 10/08/2021 tarihli 2021/10-05 sayılı karar ile alınmıştır.

Ethics committee approval was received for this study from Van Yüzüncü Yal University, Social and Human Sciences Publication Ethics Committee on 10/08/2021 and 2021/10-05 document number.

\section{Yazar Katkıları / Author Contributions:}

Fikir/Kavram/Tasarım - Idea/Concept/ Design: Z.Ç., Veri Toplama ve/veya İşleme - Data Collection and/or Processing: Z.Ç., İ.A., Analiz ve/veya Yorum - Analysis and/or Interpretation: Z.Ç., İ.A., Kaynak Taraması - Literature Review: Z.Ç., İ.A., Makalenin Yazımı - Writing the Article: Z.Ç., İ.A., Eleştirel İnceleme - Critical Review: Z.Ç., İ.A., Onay - Approval: Z.Ç., İ.A.

\section{Kaynakça / References}

Ajzen, I. (1985). From intentions to actions: A theory of planned behavior. In Action control (pp. 11-39). Springer, Berlin, Heidelberg.

Ajzen, I., \& Fishbein, M. (1969). The prediction of behavioral intentions in a choice situation. Journal of experimental social psychology, 5(4), 400-416.

Cha, S. S. (2020). Customers' intention to use robot-serviced restaurants in Korea: relationship of coolness and MCI factors. International Journal of Contemporary Hospitality Management, 32(9), 29472968.

Choe, J. Y. J., Kim, J. J., \& Hwang, J. (2021a). Perceived risks from drone food delivery services before and after COVID-19. International Journal of Contemporary Hospitality Management, 33(4), 1276-1296.

Choe, J. Y., Kim, J. J., \& Hwang, J. (2021b). Innovative marketing strategies for the successful construction of drone food delivery services: Merging TAM with TPB. Journal of Travel \& Tourism Marketing, 38(1), 16-30.

Coombs, W. N., \& Schroeder, H. E. (1988). Generalized locus of control: An analysis of factor analytic data. Personality and Individual Differences, 9(1), 79-85.

Davis, F. D., Bagozzi, R. P., \& Warshaw, P. R. (1989). User acceptance of computer technology: A comparison of two theoretical models. Management science, 35(8), 982-1003. 
Dunteman, G. H. (1989). Principal Components Analysis. Sage Publications.

Field, A. (2000). Discovering Statistics Using SPSS for Windows. London: Sage Publications.

Fishbein, M., \& Ajzen, I. (1975). Belief, Attitude, Intention and Behavior: An Introduction to Theory and Research. Addison-Wesley, Reading, MA.

Gorsuch, R. L. (1983). Factor Analysis (2nd ed.). Hillsdale, NJ: Lawrence Erlbaum.

Gramatikov, S., Kitanovski, I., Mishkovski, I., \& Jovanovik, M. (2019). Last mile delivery with autonomous vehicles: Fiction or reality.

Hair, J. F., Jr., Black, William C., Babin, B. J., \& Anderson, R. E. (2009). Multivariate Data Analysis (7th ed.). Upper Saddle River, NJ: Prentice Hall.

Henson, R. K., \& Roberts, J. K. (2006). Use of exploratory factor analysis in published research: Common errors and some comment on improved practice. Educational and Psychological measurement, 66(3), 393-416.

Hernández, E. J. U., Martínez, J. A. S., \& Saucedo, J. A. M. (2020). Optimization of the distribution network using an emerging technology. Applied sciences, 10(3), 857.

Hwang, J., \& Choe, J. Y. J. (2019). Exploring perceived risk in building successful drone food delivery services. International Journal of Contemporary Hospitality Management, 1(8), 3249-3269.

Hwang, J., \& Kim, H. (2019). Consequences of a green image of drone food delivery services: The moderating role of gender and age. Business Strategy and the Environment, 28(5), 872-884.

Hwang, J., Kim, H., \& Kim, W. (2019a). Investigating motivated consumer innovativeness in the context of drone food delivery services. Journal of Hospitality and Tourism Management, 38, 102-110.

Hwang, J., Kim, W., \& Kim, J. J. (2020). Application of the value-belief-norm model to environmentally friendly drone food delivery services. International Journal of Contemporary Hospitality Management, 32(5), 1775-1794.

Hwang, J., Lee, J. S., \& Kim, H. (2019b). Perceived innovativeness of drone food delivery services and its impacts on attitude and behavioral intentions: The moderating role of gender and age. International Journal of Hospitality Management, 81, 94-103.

Hwang, J., Kim, J. J., \& Lee, K. W. (2021). Investigating consumer innovativeness in the context of drone food delivery services: Its impact on attitude and behavioral intentions. Technological Forecasting and Social Change, 163, 120433.

Hwang, J., \& Kim, H. (2021). The effects of expected benefits on image, desire, and behavioral intentions in the field of drone food delivery services after the outbreak of COVID-19. Sustainability, 13(1), 117.

Jaramillo, F. P., Shih, K. H., \& Cheng, C. C. (2019). Can Drones Deliver Food? What the Food Delivery Industry Needs to Know. International Journal of Performance Measurement, 9(2), 41-62.

Kaoy, N. A., Lesmini, L., \& Budiman, T. (2020). Customers'acceptance in using unmanned aerial vehicles (UAV) delivery service. Advances in Transportation and Logistics Research, 3, 629-634.

Kapser, S., \& Abdelrahman, M. (2020). Acceptance of autonomous delivery vehicles for last-mile delivery in Germany-Extending UTAUT2 with risk perceptions. Transportation Research Part C: Emerging Technologies, 111, 210-225.

Kayış, A. (2005). Parametrik Hipotez Testler, SPSS Uygulamalı Çok Değişkenli İstatistik Teknikleri. Editör: Kalaycı, Ş., Ankara: Asil Yayın Dağıtım Ltd.Şti., ss.403-419.

Khan, R., Tausif, S., \& Javed Malik, A. (2019). Consumer acceptance of delivery drones in urban areas. International Journal of Consumer Studies, 43(1), 87-101.

Kim, J., \& Forsythe, S. (2008). Adoption of virtual try-on technology for online apparel shopping. Journal of Interactive Marketing, 22(2), 45-59.

Kim, J. J., \& Hwang, J. (2020). Merging the norm activation model and the theory of planned behavior in the context of drone food delivery services: Does the level of product knowledge really matter?. Journal of Hospitality and Tourism Management, 42, 1-11.

Kim, J. J., Kim, I., \& Hwang, J. (2021). A change of perceived innovativeness for contactless food delivery services using drones after the outbreak of COVID-19. International Journal of Hospitality Management, 93, 102758. 
Köse, N., \& Yengin, D. (2018). Dijital pazarlamadan fijital pazarlamaya geçişe örnek olarak artırılmış gerçeklik ve sanal gerçeklik uygulamalarının pazarlama üzerindeki katkılarının incelenmesi. İstanbul Aydın Üniversitesi Dergisi, 10(1), 77-111.

Krejcie, R. V., \& Morgan, D. W. (1970). Determining sample size for research activities. Educational and Psychological Measurement, 30, 607-610.

Macrina, G., Pugliese, L. D. P., Guerriero, F., \& Laporte, G. (2020). Drone-aided routing: A literature review. Transportation Research Part C: Emerging Technologies, 120, 102762.

Mathew, A. O., Jha, A. N., Lingappa, A. K., \& Sinha, P. (2021). Attitude towards Drone Food Delivery Services-Role of Innovativeness, Perceived Risk, and Green Image. Journal of Open Innovation: Technology, Market, and Complexity, 7(2), 144.

Mittendorf, C., Franzmann, D., \& Ostermann, U. (2017). Why Would Customers Engage in Drone Deliveries?. In AMCIS 2017 Proceedings, 1-10.

Moore, G. C., \& Benbasat, I. (1991). Development of an instrument to measure the perceptions of adopting an information technology innovation. Information systems research, 2(3), 192-222.

Nunnally, J. C. (1978). Psychometric Theory. New York: McGraw-Hill. PewInternet.

Park, J., Kim, S., \& Suh, K. (2018). A comparative analysis of the environmental benefits of drone-based delivery services in urban and rural areas. Sustainability, 10(3), 888.

Ramadan, Z. B., Farah, M. F., \& Mrad, M. (2017). An adapted TPB approach to consumers' acceptance of service-delivery drones. Technology Analysis \& Strategic Management, 29(7), 817-828.

Rogers, E. M. (1983). Diffusion of Innovations, Third Edition. The Free Press, New York.

Shahzaad, B., Bouguettaya, A., Mistry, S., \& Neiat, A. G. (2021). Resilient composition of drone services for delivery. Future Generation Computer Systems, 115, 335-350.

Sipahi, B., Yurtkoru, E.S. ve Çinko, M. (2008). Sosyal Bilimlerde SPSS'le Veri Analizi: İstanbul: Beta Yayınları.

Stevens, J. (1996). Applied Multivariate Statistics for the Social Sciences (3rd ed.). Mahwah, NJ: Lawrence Erlbaum.

Stevens, J. P. (2002). Applied Multivariate Statistics for the Social Sciences (4th ed.). New Jersey: Lawrance Erlbaum Association.

Tabachnick, B. G., \& Fidell, L. S. (2007). Using Multivariate Statistics, (5th ed.). Pearson Education: Boston.

Tabachnick, B. G. \& Fidell, L. S. (2013). Using Multivariate Statistics (6th ed.). USA: Pearson Education Limited.

Tom, N. M. F. (2020). Crashed! Why drone delivery is another tech idea not ready to take off. International Business Research, 13(7), 251-251.

Warshaw, P. R., \& Davis, F. D. (1985). Disentangling behavioral intention and behavioral expectation. Journal of Experimental Social Psychology, 21(3), 213-228.

Wu, W. Y., \& Ke, C. C. (2015). An online shopping behavior model integrating personality traits, perceived risk, and technology acceptance. Social Behavior and Personality: an international journal, 43(1), 85-97.

Vandecasteele, B., \& Geuens, M. (2010). Motivated consumer innovativeness: Concept, measurement, and validation. International Journal of Research in Marketing, 27(4), 308-318.

Yoo, W., Yu, E., \& Jung, J. (2018). Drone delivery: Factors affecting the public's attitude and intention to adopt. Telematics and Informatics, 35(6), 1687-1700. 